\title{
An analysis of targeted properties of materials used for preservation and storage of heritage collections
}

\begin{abstract}
The aim of this study was to stress the importance of investigating the properties of preservation enclosure materials in order to identify the ones that are able to protect their contents more efficiently. Since not all information on materials is covered by international standards and technical specifications, nine paper-based materials used for making preservation enclosures (file folders, passepartouts, boxes etc.) were investigated. A selective analysis of the materials' properties was carried out to determine smoothness, water absorptiveness, water wettability, water vapor permeability, tensile strength, folding endurance, bursting strength, puncture strength, as well as loss of bursting strength caused by dry heat and 100\% RH. Results obtained from measuring smoothness, water absorptiveness, water wettability and water vapor transmission rate indicate that a material outside of ISO 16245:2009 grammage requirements for making file covers can exhibit more desirable properties than the one that meets multiple standards for storage and preservation. Additionally, results showed that bursting strength of enclosure materials was significantly affected by both extreme microclimate conditions. However, 100\% RH had affected bursting strength of the investigated materials more than dry heat. The presented procedure proved to be a useful indicator of materials' properties within the context of heritage collections preservation and storage.
\end{abstract}

\author{
Gabriela Aleksić ${ }^{1}$ \\ Tomislav Cigula ${ }^{2}$ \\ Suzana Pasanec \\ Preprotić $^{2}$ \\ ${ }^{1}$ National and University Library in \\ Zagreb, Croatia \\ ${ }^{2}$ University of Zagreb, Faculty of \\ Graphic Arts, Zagreb, Croatia \\ Corresponding author: \\ Gabriela Aleksić \\ e-mail: \\ galeksic@nsk.hr
}

First recieved: 30.8.2021.

Accepted: 26.10.2021.

\section{KEY WORDS}

preservation enclosures, heritage collections, preservation

\section{Introduction}

Library, archival and museum heritage collections consist of items made of materials such as leather, parchment, wood, metals, textiles, paper-based materials, waxes, inks and colorants, which are vulnerable to various external factors. Damage to and deterioration of these materials can occur due to exposure to inappropriate temperature and relative humidity ( $\mathrm{RH})$, light, UV radiation, dust particles, airborne pollutants, pests or poor handling. One of the methods to reduce or limit the effect of those factors is based on using preservation enclosures during storage, circulation, exhibitions and transport. In the Library Materials Preservation Manual (1983), enclosure is described as an envelope or a container providing protection for an item (Balloffet and Hille, 2005). Depending on their service life, enclosures can be divided into two types: temporary and permanent. Additionally, based on their contact with an item, enclosures can either be primary or secondary.

Some of the most important features of preservation enclosures are their functionality, appearance and the materials they are made of. Preservation enclosures are mainly made of paper-based materials, but may contain polyester films, bookcloth or twill tape in order to provide appropriate protection for an item. Previous studies have provided an insight into protective performance 
of both historical and new preservation boxes in case of water damage and fluctuating RH (Schönbohm et al., 2010; Singer, 2010). However, few studies have focused on the properties of materials used for making custom preservation enclosures (Velensek et al., 2014). Although the characteristics of enclosure materials are described by international standards and provided by manufacturer specifications, previous studies have indicated that the existing standards are insufficient and do not guarantee paper quality (Havermans, 1995; Havermans, 2002). Furthermore, although it is well known that the quality of enclosure materials should meet the highest standards of preservation practice, our understanding of their required properties is limited. Basic requirements for preservation enclosure materials include chemical stability, smoothness, water resistance, mechanical resistance and barrier resistance. Enclosures are also expected to be space-saving and weight minimizing in nature. Enclosure materials should either be $\mathrm{pH}$ neutral or alkaline-buffered, depending on the type of item they are intended to preserve and the purpose of use. Alkaline-buffered paper can adsorb volatile acidic compounds more successfully than neutral paper (Meyer et al., 2014), but the long-term consequences of the process are still unclear (Meyer and Volland, 2017). Alkaline paper will also remain acid-free for a longer period of time. However, alkaline materials can be degradative for certain works of art on paper (Kolar, 1997; Meyer and Volland, 2017) and contemporary colour materials (The Library of Congress, n.d.).

This study was designed to establish a procedure for evaluation of enclosure materials, which will ultimately help identify the materials with most desirable properties. We also aimed to review targeted properties of different paper-based enclosure materials in order to gain insight into their protective performance under various threats. Enclosure materials were investigated selectively, based on their specific purpose of use. We investigated smoothness, water resistance, mechanical resistance and water vapor permeability of the materials, as well as characteristics related to their targeted properties.

\section{Experimental}

\section{Materials}

Nine commercial paper-based materials used for making both short- and long-term custom preservation enclosures were included in this study. The descriptive characteristics of the materials are given in Table 1. Applications

\section{Table 1}

The descriptive characteristics of the investigated materials

\begin{tabular}{l|l|l|l}
\hline Code Name & \multicolumn{1}{|c|}{ Name and description } & \multicolumn{1}{c}{ Grammage $\mathbf{( g / \mathbf { m } ^ { 2 } )}$} & \multicolumn{1}{c}{ Manufacturer } \\
\hline ING & Ingres paper, white & $90 \pm 3 \%$ & Fabriano / Fedrigoni Group \\
\hline VERG & Vergé paper, natural white, ribbed surface & 100 & Hahnemühle FineArt GmbH \\
\hline ELF & Elephant hide paper, chamois & 110 & Zanders Mill / Reflex GmbH \& Co. KG \\
\hline NETT & Nettuno board, perla & $280 \pm 5 \%$ & Fedrigoni Group \\
\hline PASS & Mounting board, natural white & 400 & Hahnemühle FineArt GmbH \\
\hline SL1 & Grey board, pasted extra smooth & $1000 \pm 5 \%$ & Reno de Medici Group, OVARO S.p.A. \\
\hline SL 2 & Grey board, pasted extra smooth & $1555 \pm 5 \%$ & Reno de Medici Group, OVARO S.p.A. \\
\hline MK1 & Museumkarton, crème & 800 & Royal Moorman Karton \\
\hline MK 2 & Museumkarton, ivory & 1200 & Royal Moorman Karton \\
\hline
\end{tabular}

Table 2

Applications and quality characteristics of investigated materials

\begin{tabular}{l|l|l}
\hline Code Name & \multicolumn{1}{|c|}{ Applications of the materials / Type of encasement } & \multicolumn{1}{c}{ Quality standards and ecological features } \\
\hline ING & sleeve, wrapper, interleaving & $\begin{array}{l}\text { ISO 2470 (R457), TAPPI 502-98, ISO 9706:1994, } \\
\text { FSC recycled, Elemental chlorine-free, CE 94/62 }\end{array}$ \\
\hline VERG & sleeve, file cover, wrapper, interleaving & $\begin{array}{l}\text { DIN 6738:2007-03, ANSI/NISO Z39.48-1992, } \\
\text { ISO 9706:1994, ISO 16245:2009, Standard-PAT, Color-PAT }\end{array}$ \\
\hline ELF & covering paper for boxes, portfolios and slipcases & FSC-STD-40-004, ASI-ACC-016 \\
\hline NETT & envelope, three-sided folder, phase box & $\begin{array}{l}\text { ISO 2470 (R457), TAPPI 502-98, ISO 9706:1994, } \\
\text { FSC recycled, Elemental chlorine-free, CE 94/62 }\end{array}$ \\
\hline PASS & frame, three-sided folder, microfilm reel identification tag & $\begin{array}{l}\text { DIN 6738:2007-03, ANSI/NISO Z39.48-1992, } \\
\text { ISO 9706:1994, ISO 16245:2009, Standard-PAT, Color-PAT }\end{array}$ \\
\hline SLJ 1 & portfolio & ISO 2470-1:2016, ISO 287:2017, FSC recycled \\
\hline SLJ 2 & box, portfolio, slipcase & ISO 2470-1:2016, ISO 287:2017, FSC recycled \\
\hline MK1 & portfolio, passepartout & $6738: 2007-03$, ANSI/NISO Z39.48-1992, ISO 9706:1994 \\
\hline MK 2 & slipcase, box, passepartout & $6738: 2007-03$, ANSI/NISO Z39.48-1992, ISO 9706:1994 \\
\hline
\end{tabular}


of the materials, as well as relevant standard compliances and ecological features provided by the manufacturer are shown in Table 2.

\section{Characterization methods}

Characterization of the materials included determining the thickness and moisture content of the samples. Thickness of five materials was measured by an Enrico Toniolo DGTB01 digital micrometer, while moisture content of the nine materials was determined using an O'Haus MB 45 moisture analyser at $105^{\circ} \mathrm{C}$.

\section{Smoothness}

Preservation enclosure materials should be free of topographic features and very smooth, in order to repel dust (International Organization for Standardization, 1998) and prevent mechanical damage to surrounding items. The common devices for determining topographic features of a paper surface include air leak testers, optical contact testers, surface profilers and numerous ink and liquid application tools (Singh, 2008). One of the three most common air leakage methods is the Bekk method, which presents the time interval required for vacuum pressure to drop from $50.7 \mathrm{kPa}$ to $48.0 \mathrm{kPa}$ (Petric Maretić et al., 2018).

In this study, Bekk smoothness of only five materials was determined, as the method is not recommended for materials with thickness over $0.5 \mathrm{~mm}$ or very permeable materials (International Organization for Standardization, 1995).

\section{Water Resistance}

Water outbreaks are a common threat to heritage collections. They can occur as a result of a technical failure, an accident, a human error or during natural disasters. The extent of damage caused by water can vary, as penetration is affected by factors such as porous structure, contact angle, wetting time, fibre swelling and diffusion (Sönmez and Özden, 2018).

To investigate water resistance of the materials, two types of tests were employed: the water absorptiveness and the water wettability test. Both of the properties tested describe the paper's reaction to water deposited on a specific area of paper within a defined time and are highly undesirable in enclosure materials.

Measurements of water absorptiveness were conducted with a FRANK water absorption apparatus, as described in ISO 535:2014 (E). Testing times were adjusted to both Cobb60 (paper) and Cobb120 (boards), according to the rate of the water absorption of the materials. Water absorptiveness was calculated using (1).
$A=\left(m_{2}-m_{1}\right) F$

where A- water absorptiveness $\left(\mathrm{g} / \mathrm{m}^{2}\right), \mathrm{m}_{1}$ - dry mass of the sample in grams, $\mathrm{m}_{2}$ - wet mass of the sample in grams, $F=10000 / 100 \mathrm{~cm}^{2}$ (test area)

\section{Water wettability}

The water contact angle describes the interaction of water with a solid surface (Huhtamäki et al., 2018) and depends on surface geometry, roughness, contamination and deformation (Marmur et al., 2017). Maximum wetting occurs with the angle of $0^{\circ}$. For contact angles below $90^{\circ}$, materials are considered hydrophilic, while for values above $90^{\circ}$, they are classified as hydrophobic. For values over $150^{\circ}$ they are considered superhydrophobic (Vuckovac et al., 2019).

The measurements of contact angle were carried out with a DataPhysics' OCA 30 device. Distilled water was used as a test liquid and drop volume was set to $1 \mu$ l. The sessile drop method was utilized. Contact angle measurements were conducted $0.5 \mathrm{~s}$ after the initial water-substrate contact, using Young-Laplace fitting.

\section{Water vapor barrier resistance}

Efficiency of preservation enclosures is determined by their ability to act as a barrier. The most important barrier properties include resistance to water vapor, air, odour, gases, grease or oil, but this can vary depending on the area of use (Sönmez and Özden, 2018). Water vapor permeability of the materials was investigated due to its relationship with water outbreaks.

Water vapor transmission rate (WVTR) of the materials was determined using the Cup method principle (Labthink, 2016). The apparatus consisted of a test dish with an open mouth measuring $35 \mathrm{~mm}$ in diameter. The dish was filled with distilled water, sealed with a lid holding a sample and placed in a desiccator containing silica gel for water vapor absorption. The test was conducted at $22 \pm 1^{\circ} \mathrm{C}$ and $50 \pm 2 \%$. Weightings of the test dish were repeated after 24 and 48 hours. WVTR was calculated using (2):

$W V T R=\Delta m / \Delta t A$

where $\Delta \mathrm{m}$ - sample weight change (g), $\Delta \mathrm{t}$ - time between weighing (day), $A$ - test sample area $\left(\mathrm{m}^{2}\right)$

\section{Mechanical Resistance}

Accidental mechanical damage to an item can happen during transport and manipulation or as a result of an earthquake. Therefore, good mechanical resistance is considered a desirable property of enclosure materials. 
In this experiment, four types of strength properties were evaluated: tensile strength, folding endurance, puncture strength and bursting strength.

Folding endurance measurements were conducted using a FRANK device (Schopper type), model 840 (1974) with a tension spring range between 1 and $1.3 \mathrm{kp}$. This device is suitable for paper with thickness up to 0,25 $\mathrm{mm}$ (International Organization for Standardization, 1993). However, all three materials that usually get folded during use were tested, regardless of their suitability. Folding endurance (F) was calculated using (3):

$F=\log _{10} d$

where F-folding endurance, $d$ - number of folds

A FRANK device, type 800 (1973.), with a vertical force measurement system and a maximum load of $30 \mathrm{kp}$ was used in tensile force measurement. Tensile strength ( $T$ ) was calculated using (4):

$T=F / W$

where $\mathrm{F}$ - the tensile force $(\mathrm{N}), \mathrm{w}$ - the strip width $(\mathrm{mm})$

Due to grammage differences of the materials (Luo, 2019), a tensile index (TI) was calculated using (5) to facilitate comparison.

$T I=(T / R) 1000$

where $\mathrm{TI}$ - the tensile index ( $\mathrm{Nm} / \mathrm{g}), \mathrm{T}$ - the tensile strength $(\mathrm{kN} / \mathrm{m}), \mathrm{R}$ - grammage $\left(\mathrm{g} / \mathrm{m}^{2}\right)$

Robust enclosures made of boards are expected to provide a higher degree of protection for an item, so all types of boards (NETT, PASS, SLJ1, SLJ2, MK1, MK2) were tested for bursting and puncture strength.

Puncture strength was determined by a Frank PTI puncture tester, type 53809, in compliance with the ISO 3036 standard, while a Lorentzen \& Wettre Bursting Strength Tester SE 181 was used in bursting strength measurements, in compliance with the ISO 2759 standard.

Burst index (BI) was calculated using (6):

$B I=B S / R$

where BS- bursting strength $(\mathrm{kPa}), \mathrm{R}$ - grammage $\left(\mathrm{g} / \mathrm{m}^{2}\right)$

\section{Samples preparation}

Prior to testing, all samples were conditioned for $24 \mathrm{~h}$ at $23 \pm 2{ }^{\circ} \mathrm{C}$ and $50 \pm 5 \% \mathrm{RH}$, as specified in ISO 187. To determine change in the bursting strength of the materials exposed to extreme microclimate conditions (high $\mathrm{RH}$ and high temperature), two additional sets of samples were prepared. Samples from the first set were placed in a desiccator and exposed to $\mathrm{RH}$ level of $100 \%$ at $23 \pm 2$ ${ }^{\circ} \mathrm{C}$ for 48 hours. Samples from the second set were dried out at the temperature of $105^{\circ} \mathrm{C}$ in the moisture analyser.

\section{Results and Discussion}

The measurements were repeated at least 5 times, and tables and figures in this section report average values and standard deviations where applicable.

Table 3 shows the thickness and moisture content of the investigated materials. It was observed that the moisture content is not dependant on the thickness of the material, although both properties affect the material's behaviour and end-use performance (Li, Ramaswamy and Bjegovic, 2003).

\section{Table 3}

Characterization of the materials in terms of thickness and moisture content

\begin{tabular}{l|c|c}
\hline $\begin{array}{c}\text { Code } \\
\text { Name }\end{array}$ & Thickness (mm) ISO 534 & Moisture content (\%) \\
\hline ING & 0.14 & 5.13 \\
\hline VERG & 0.16 & 5.49 \\
\hline ELF & 0.13 & 5.57 \\
\hline NETT & 0.39 & 5.39 \\
\hline PASS & 0.63 & 5.82 \\
\hline SLJ 1 & $1.4^{*}$ & 6.47 \\
\hline SLJ 2 & $2.4^{*}$ & 6.21 \\
\hline MK 1 & $1.1^{*}$ & 5.37 \\
\hline MK 2 & $1.6^{*}$ & 5.59 \\
\hline
\end{tabular}

* Values provided by the manufacturer

\section{Smoothness, water absorptiveness and contact angle}

As material's surface properties usually differ on each side, some tests were conducted on both the wire (W) and the felt (F) side of the samples. The results of the materials' smoothness, water absorptiveness and contact angle are shown in Table 4.

As it mentioned before, the Bekk method is not recommended for materials with thickness over $0.5 \mathrm{~mm}$, so SLJs and MKs have not been tested. Although the values of smoothness ranged widely, we noticed that materials used for similar purposes (e.g. ING and VERG or NETT and PASS) show similar smoothness values. The F-side of all five materials proved to have the highest levels of smoothness. This is a desirable property since the F-side of the material is frequently facing the object in need of protection. The largest difference in smoothness values of $\mathrm{W}$ - and F- side was observed in VERG, which can be attributed to the ribbed finish surface on the $\mathrm{W}$-side. 


\section{Table 4}

Smoothness, water absorptiveness and contact angle with water on each side of the materials

\begin{tabular}{|c|c|c|c|c|}
\hline $\begin{array}{c}\text { Code } \\
\text { name }\end{array}$ & $\begin{array}{c}\text { Sample } \\
\text { side }\end{array}$ & Smoothness (s) & \begin{tabular}{|c|} 
Water \\
absorptiveness \\
$\left(\mathrm{g} / \mathrm{m}^{2}\right)$
\end{tabular} & $\begin{array}{l}\text { Contact } \\
\text { angle }\left({ }^{\circ}\right)\end{array}$ \\
\hline \multirow{2}{*}{ ING } & W & $42.98 \pm 1.0$ & $21.28 \pm 0.89 *$ & $114.25 \pm 3.98$ \\
\hline & $\mathrm{F}$ & $46.04 \pm 2.37$ & $22.67 \pm 0.71^{*}$ & $114.79 \pm 2.70$ \\
\hline \multirow{2}{*}{ VERG } & W & $20.68 \pm 1.12$ & $25.77 \pm 0.87^{*}$ & $95.62 \pm 3.24$ \\
\hline & $\mathrm{F}$ & $47.18 \pm 0.83$ & $23.66 \pm 0.55^{*}$ & $98.78 \pm 4.92$ \\
\hline \multirow{2}{*}{ ELF } & W & $240.83 \pm 13.66$ & $13.62 \pm 0.65^{*}$ & $68.62 \pm 2.73$ \\
\hline & $\mathrm{F}$ & $255.66 \pm 13.66$ & $14.58 \pm 0.54^{*}$ & $85.14 \pm 7.57$ \\
\hline \multirow{2}{*}{ NETT } & W & $13.64 \pm 1.22$ & $36.50 \pm 0.49 * *$ & $114.37 \pm 4.44$ \\
\hline & $\mathrm{F}$ & $14.48 \pm 1.49$ & $35.65 \pm 0.68 * *$ & $114.49 \pm 2.47$ \\
\hline \multirow{2}{*}{ PASS } & W & $10.92 \pm 0.89$ & $31.25 \pm 0.97 * *$ & $121.58 \pm 0.86$ \\
\hline & $\mathrm{F}$ & $17.94 \pm 0.74$ & $28.38 \pm 1.08 * *$ & $124.72 \pm 6.54$ \\
\hline \multirow{2}{*}{ SLJ 1} & W & $\mathrm{n} / \mathrm{a}$ & $415.3 \pm 8.69 * *$ & $86.37 \pm 4.85$ \\
\hline & $\mathrm{F}$ & $\mathrm{n} / \mathrm{a}$ & $423.24 \pm 6.10 * *$ & $110.03 \pm 4.76$ \\
\hline \multirow{2}{*}{ SLJ 2} & W & $\mathrm{n} / \mathrm{a}$ & $\mathrm{n} / \mathrm{a}$ & $113.65 \pm 2.88$ \\
\hline & $\mathrm{F}$ & $\mathrm{n} / \mathrm{a}$ & $\mathrm{n} / \mathrm{a}$ & $116.05 \pm 1.85$ \\
\hline \multirow{2}{*}{ MK 1} & W & $\mathrm{n} / \mathrm{a}$ & $\mathrm{n} / \mathrm{a}$ & $116.13 \pm 3.42$ \\
\hline & $\mathrm{F}$ & $\mathrm{n} / \mathrm{a}$ & $\mathrm{n} / \mathrm{a}$ & $119.92 \pm 0.51$ \\
\hline \multirow{2}{*}{ MK 2} & W & $\mathrm{n} / \mathrm{a}$ & $32.56 \pm 0.26 * *$ & $113.05 \pm 2.84$ \\
\hline & $\mathrm{F}$ & $\mathrm{n} / \mathrm{a}$ & $33.69 \pm 0.21 * *$ & $116.06 \pm 3.59$ \\
\hline
\end{tabular}

${ }^{*}$ Cobb60 - testing time of $60 \mathrm{~s},{ }^{*}$ Cobb120 - testing time of $120 \mathrm{~s}$

Compared to other investigated materials, ELF shows the highest levels of smoothness (from 6 to over 20 times). A significant difference in results between ELF and other four materials (ING, VERG, NETT, PASS) could be attributed to the fact that glossy paper is more topographically uniform compared to the matte one (Quintana, Gómez and Villar, 2012).

By testing water absorptiveness and water wettability, we aimed to determine water resistance of the materials. Water absorptiveness was investigated according to the water uptake rate of the materials, where paper (ING, VERG, ELF) was tested for $60 \mathrm{~s}$, while the boards (NETT, PASS, MK 2, SLJ 1) were tested for $120 \mathrm{~s}$. Two materials (SLJ 2, MK 1) were excluded from the water absorptiveness test, since another material from the same manufacturer (SL 1, MK 2) was more suitable for comparison purposes in terms of grammage.

The results (Table 4) obtained from paper show no distinctive difference in water absorptiveness between the W-and the F- side. Results for ING and VERG are similar, while ELF shows the lowest water absorptiveness in the group, which can be attributed to its more compact surface.

Cobb120 results show that the values of SLJ 1 significantly differ compared to those of the other three boards (over 10 times higher water absorptiveness). Although SLJ 1 is described by the manufacturer as a smooth board, it seems to have a more porous surface than other investigated materials, as it enables a much faster water uptake.

The results of contact angle measurements confirmed that most materials (with an exception of ELF) show hydrophobic behaviour (Table 4). Compared to the values of water absorptiveness, the contact angle values show a higher standard deviation. As the measuring area of the water absorptiveness occupies $112.8 \mathrm{~mm}$ $\pm 0.2 \mathrm{~mm}$ and the water droplet in the contact angle test takes up less than $1 \mathrm{~mm}^{2}$, this could be attributed to inhomogeneous surface of the materials.

The water absorptiveness and contact angle values suggest that most often low water wettability indicates low water absorptiveness. In two materials (ELF, SLJ 1) no such relationship had been noted, which can be attributed to the compact surface of ELF and the porous structure of $S L J 1$, in which the inner structure of the material plays an important role in water uptake.

\section{Water vapor transmission rate (WVTR)}

The WVTR values confirmed that water vapor barrier resistance is not exclusively dependant on grammage. We observed that lower levels of smoothness could indicate higher WVTR (Table 4, Figure 1). However, since four heavier boards (SLJS, MKs) were not applicable for smoothness measurements, general conclusions could not be drawn.

We observed that four thicker boards (MKs, SLJs) show very low WVTR (Figure 1), which could be attributed to their multiple layer structure. The data also suggest that MK 2 shows both lower WVTR and water absorptiveness than SLJ 1, although both are similar in thickness.

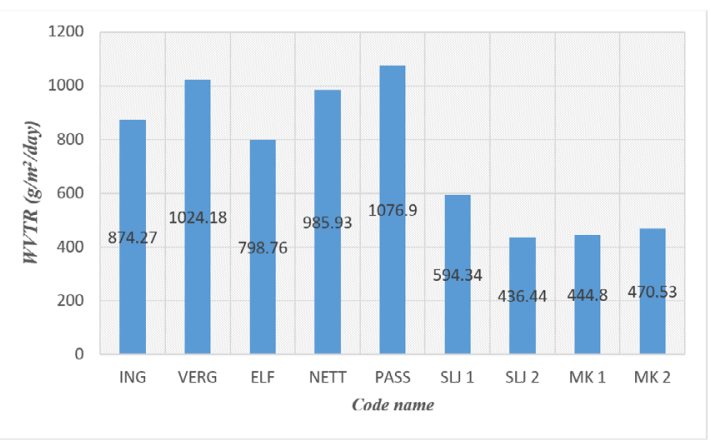

» Figure 1: Water vapor transmission rate $\left(\mathrm{g} / \mathrm{m}^{2} /\right.$ day) of the materials

The highest levels of WVTR were obtained from PASS, which also displays low levels of smoothness and water absorptiveness, as well as the lowest water wettability of all materials used in the tests. 


\section{Folding endurance and tensile strength}

Thinner materials (ING, VERG, NETT) were tested for folding endurance and tensile strength in order to determine their behaviour under tension conditions. The measurements excluded ELF (usually used as a covering paper for a board) as it rarely experiences tension conditions. However, NETT was included in the test despite exceeding thickness of up to $0.25 \mathrm{~mm}$ recommended by the standard (International Organization for Standardization, 1993) as it experiences both folding and tensile stress during shelf life. Number of folds and tensile force of the materials were obtained both crosswise and lengthwise. Since the test values are normally higher lengthwise than crosswise, the tensile index and folding endurance were calculated to observe strength properties of the materials in each direction, regardless of the grammage.

Folding endurance of NETT (the material used for making phase boxes) was evaluated according to the requirement that a box should be able to open and close at least 300 times (International Organization for Standardization, 2009). The results (Table 5) showed that NETT withstands over 300 foldings in both fibre directions.

\section{Table 5}

Tensile stretch, tensile index and folding endurance of three materials in both fibre directions

\begin{tabular}{l|c|c|c|c}
\hline $\begin{array}{c}\text { Code } \\
\text { name }\end{array}$ & $\begin{array}{c}\text { Fibre } \\
\text { orientation }\end{array}$ & $\begin{array}{c}\text { Tensile } \\
\text { stretch } \\
\mathbf{( m m )}\end{array}$ & $\begin{array}{c}\text { Tensile } \\
\text { index } \\
\mathbf{( N m / g )}\end{array}$ & $\begin{array}{c}\text { Folding } \\
\text { endurance } \\
\mathbf{( F )}\end{array}$ \\
\hline \multirow{2}{*}{ ING } & $\mathrm{CD}$ & $4.42 \pm 0.52$ & 39.38 & 2.42 \\
\cline { 2 - 5 } & $\mathrm{MD}$ & $1.02 \pm 0.08$ & 46.06 & 2.57 \\
\hline \multirow{2}{*}{ VERG } & $\mathrm{CD}$ & $2.85 \pm 0.85$ & 22.56 & 2.28 \\
\cline { 2 - 5 } & $\mathrm{MD}$ & $1.15 \pm 0.3$ & 44.31 & 2.74 \\
\hline \multirow{2}{*}{ NETT } & $\mathrm{CD}$ & $5.24 \pm 0.43$ & 38.54 & 2.48 \\
\cline { 2 - 5 } & $\mathrm{MD}$ & $1.82 \pm 0.28$ & 64.93 & 2.94 \\
\hline
\end{tabular}

Although the results of folding endurance for each sample varied widely, the tensile strength measurements suggest that both tensile stretch and tensile index could roughly predict folding endurance in each direction. The strong influence of tensile strength on folding endurance was also mentioned by previous studies (Williams and Krasow, 1973).

The results of both folding endurance and tensile index of ING show that the difference between the values crosswise and lengthwise is significantly lower than in the other two materials, which could be attributed to better strength, inter-fibre bonding and arrangement of the fibres (Caulfield and Gunderson, 1988; Karlovits and Gregor-Svetec, 2012). Compared to the other two materials (VERG, NETT), ING also shows the highest tensile index crosswise and the lowest tensile stretch lengthwise (Table 5).

\section{Puncture and bursting strength}

The boards were tested for puncture and bursting strength, as they preserve both heritage items and other, more fragile enclosures (file folders, sleeves) and are expected to protect their contents more efficiently.

The data shown in Table 6 suggest that both puncture and bursting strength generally increase with thickness and grammage of the material. However, we observed that in materials with a multiple layer structure (SLJs, MKs), puncture and bursting strength values are not dependant on grammage and thickness, but may be affected by the uniformity and compactness of the layers. The highest values of burst index were found in NETT, which also exhibits good tensile strength and folding endurance. Compared to grey boards (SLJs), museum boards (MKs) show higher resistance to puncture and bursting stress.

\section{Table 6}

Puncture strength and bursting strength of the materials after an exposure to dry heat* and high $\mathrm{RH}^{* *}$

\begin{tabular}{l|c|c|c|c}
\hline $\begin{array}{c}\text { Code } \\
\text { name }\end{array}$ & $\begin{array}{c}\text { Puncture } \\
\text { strength } \\
\text { (J) }\end{array}$ & $\begin{array}{c}\text { Bursting } \\
\text { strength } \\
\text { ISO 187 } \\
\text { (kPa) }\end{array}$ & $\begin{array}{c}\text { Bursting } \\
\text { strength* } \\
\text { (kPa) }\end{array}$ & $\begin{array}{c}\text { Bursting } \\
\text { strength** } \\
\text { (kPa) }\end{array}$ \\
\hline NETT & $2.07 \pm 0.04$ & $603.3 \pm 22.2$ & $455.6 \pm 25.38$ & $466 \pm 13.14$ \\
\hline PASS & $2.5 \pm 0$ & $595.4 \pm 36.3$ & $493.8 \pm 41.02$ & $n / a$ \\
\hline SL1 1 & $4.99 \pm 0.03$ & $1306 \pm 45.9$ & $1073.8 \pm 63.91$ & $972.8 \pm 38.81$ \\
\hline SLJ 2 & $8.95 \pm 0.09$ & $1837.1 \pm 71.9$ & $1457.2 \pm 69.34$ & $1313 \pm 64.68$ \\
\hline MK1 & $5.45 \pm 0.41$ & $1536.89 \pm 67.1$ & $1188 \pm 122.56$ & $888.6 \pm 52.88$ \\
\hline MK 2 & $8.44 \pm 0.21$ & $2540.8 \pm 96.1$ & $1872.6 \pm 99.31$ & $1713.4 \pm 90.29$ \\
\hline
\end{tabular}

*bursting strength of the materials subjected to dry heat, **bursting strength of the materials subjected to high $\mathrm{RH}$

\section{Bursting strength of materials under extreme microclimate conditions}

Hygroscopic materials such as paper react to changes in $\mathrm{RH}$ by absorbing moisture from the environment in order to reach concentration equilibrium. To investigate how changes in moisture content affect strength properties of the materials, we designed two tests in which the samples were tested for bursting strength after being subjected to dry heat and high $\mathrm{RH}$.

The results of the bursting strength measurements (Table 6) show that materials react to both dry heat and high $\mathrm{RH}$ with a decrease in bursting strength. However, high RH proved to have a more significant effect on the bursting strength of most materials than dry heat (with exception of NETT).

The bursting strength of PASS subjected to high $\mathrm{RH}$ was not included, as it was outside the measurement range of the pressure gauge $(290.7 \mathrm{kPa})$. 
We also observed that materials with a higher burst index (NETT, MKs) are more sensitive to changes caused by both dry heat and high RH (Figure 2).

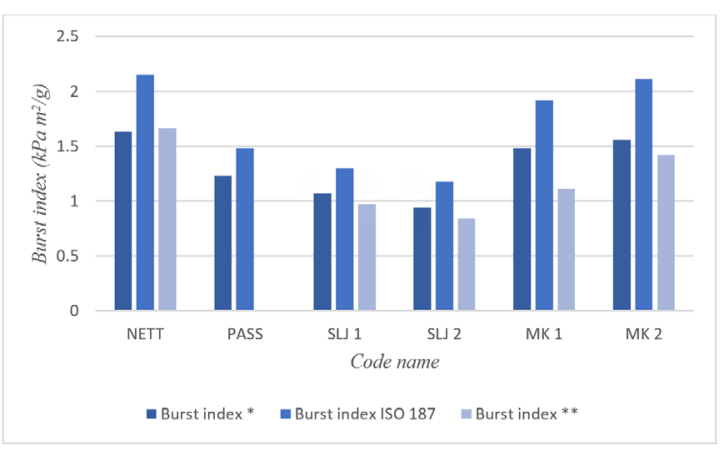

» Figure 2: Burst index of the materials before and after exposure to dry heat* and high $\mathrm{RH}^{* *}$

\section{Conclusions}

This study was conducted in order to investigate targeted properties of the paper-based materials that could be used (or already are in use) for making custom preservation enclosures. Since not all information on materials is covered by international standards and technical specifications, additional methods needed to be employed.

Selective investigation of the materials' properties was carried out to evaluate smoothness, water absorptiveness, water wettability, water vapor permeability, tensile strength, folding endurance, bursting strength, puncture strength, as well as loss of bursting strength caused by dry heat and $100 \% \mathrm{RH}$.

By observing the results, the following was concluded:

- Smoothness, water absorptiveness, water wettability and WVTR results obtained from ING confirm that a material outside of ISO 16245:2009 grammage requirements $\left(90 \mathrm{~g} / \mathrm{m}^{2}\right.$ instead of 100 $\mathrm{g} / \mathrm{m}^{2}$ ) for making file covers can exhibit more desirable properties than the one that meets multiple standards for storage and preservation (VERG). - Bursting strength of the materials was significantly affected by both high humidity and dry heat. However, high $\mathrm{RH}$ had a bigger impact on bursting strength of the investigated materials.

- Despite its hydrophilic behaviour, the surface finished material (ELF) shows both the lowest water absorptiveness and the lowest WVTR compared to other materials of similar grammage.

- The results do not indicate the need to perform both puncture and bursting strength tests, as they result in similar relations between the investigated materials.
- Determining the contact angle did not provide an insight into water absorptiveness and barrier resistance to water vapor of the materials, so it is advisable to exclude it from future analyses.

To conclude, the presented procedure proved to be a useful indicator of materials' properties within the context of heritage collections preservation and storage.

\section{Acknowledgements}

The authors thank Branka Lajić of the Faculty of Graphic Arts at the University of Zagreb for the help with puncture strength measurements.

\section{References}

Balloffet, N. \& Hille, J. (2005) Preservation and Conservation for Libraries and Archives. Chicago, USA: American Library Association.

Caulfield, D. F. \& Gunderson, D. E. (1988) Paper Testing and Strength Characteristics. In: TAPPI proceedings of the 1988 paper preservation symposium, 19-21 October 1988, Washington DC, USA. Washington DC: TAPPI Press. pp. 31-40.

Havermans, J. (1995) Effects of Air Pollutants on the Accelerated Ageing of Cellulose-based Materials. Restaurator. 16, 209-233. Available from: doi: 10.1515/rest.1995.16.4.209

Havermans, J. (2002) The Impact of European Research Related to Paper Ageing on Preventive Conservation Strategies. Restaurator. 23 (2), 68-76. Available from: doi: 10.1515/REST.2002.68 Huhtamäki, T., Tian, X., Korhonen, J. T. \& Ras, R. H. A. (2018) Surface-wetting characterization using contact-angle measurements. Nature Protocols. 13 (7), 1521-1538. Available from: doi: 10.1038/s41596-018-0003-z

International Organization for Standardization (1993) ISO 5626:1993. Paper - Determination of folding endurance. Geneva, International Organization for Standardization. International Organization for Standardization (1995) ISO 5627:1995. Paper and board - Determination of smoothness (Bekk method). Geneva, International Organization for Standardization.

International Organization for Standardization (1998) ISO 11800:1998. Information and documentation - Requirements for binding materials and methods used in the manufacture of books. Geneva, International Organization for Standardization. International Organization for Standardization (2009) ISO 16245:2009. Information and documentation - Boxes, file covers and other enclosures, made from cellulosic materials, for storage of paper and parchment documents. Geneva, International Organization for Standardization. 
Karlovits, M. \& Gregor-Svetec, D. (2012) Durability of cellulose and synthetic papers exposed to various methods of accelerated ageing. Acta Polytechnica Hungarica. 9 (6), 81-100.

Kolar, J. (1997) Mechanism of Autoxidative Degradation of Cellulose. Restaurator, 163-176. Available from: doi: 10.1515/rest.1997.18.4.163

Labthink (2016) An Outline of Standard ASTM E96 for Cup Method Water Vapor Permeability Testing. Available from: http://en.labthink.com/en-us/literatures/an-outline-of-standard-for-cup-method-water-vapor-permeability-testing.html [Accessed: 17th July 2021].

Li, P. Y., Ramaswamy, S. \& Bjegovic, P. (2003) Pre-emptive control of moisture content in paper manufacturing using surrogate measurements. Transactions of the Institute of Measurement and Control. 25 (1), 36-56. Available from: doi: 10.1191/0142331203tm070oa

Luo, Y. (2019) Durability of Chinese Repair Bamboo Papers under Artificial Aging Conditions. Studies in Conservation. 64 (8), 448-455. Available from: doi: 10.1080/00393630.2019.1608706

Marmur, A.. Volpe, C. D., Siboni, S. Amirfazli, A. \& Drelich, J. W. (2017) Contact angles and wettability: Towards common and accurate terminology. Surface Innovations. 5 (1), 3-8. Available from: doi: 10.1680/jsuin.17.00002

Meyer, F., Hansen, D., Knjasev, V. \& Volland, G. (2014) The "Schinkel's legacy" project at the Kupferstichkabinett Berlin: Air quality in storage cabinets - Cause and effect. Restaurator. 35 (2), 81-112.

Meyer, F. \& Volland, G. (2017) A New Housing Concept for the Karl Friedrich Schinkel Collection: Chemical and Mechanical Aspects. Restaurator. 38 (1), 1-31.

Petric Maretić, K., Rudolf, M., Bates, I. \& Plazonić, I. (2018) The comparison of topographic paper surface characteristics based on roughness and smoothness. In: Žiljak Gršić, J. (ed.) Printing \& Design 2018: Proceedings of the International Scientific Conference Printing \& Design, 16-17 March 2018, Zagreb, Croatia. Zagreb: Akademija Tehničkih Znanosti Hrvatske - Centar za grafičko inženjerstvo. pp. 136-142.
Quintana, E., Gómez, N. \& Villar, J. C. (2012) Influence of roughness and chemical surface properties on print quality of coated papers. Appita Journal. 65 (3), 262-268.

Schönbohm, D., Glück, E., Kühner, M. \& Banik, G. (2010) Protective enclosures for art on paper, archives and library materials. Restaurator. 31 (3), 286-303. Available from: doi: 10.1515/rest.2010.020

Singer, H. (2010) Evacuating the high bay racking system at the Albertina Museum in Vienna after a water entry in June 2009. Restaurator. 31 (3-4), 265-285. Available from: doi: 10.1515/rest.2010.019

Singh, S. P. (2008) A comparison of different methods of paper surface smoothness evaluation. BioResources. 3 (2), 503-516.

Sönmez, S. \& Özden, Ö. (2018) Barrier properties of paper and cardboard. In: Salman, S. (ed.) Academic Researches In Architecture, Engineering Planning And Design. Ankara, Turkey, Gece Kitaplığı, pp. 171-183.

The Library of Congress (n.d.) Care, Handling, and Storage of Photographs. Available from: https://www.loc.gov/preservation/care/ photo.html [Accessed: 5th August 2021].

Velensek, N., Meyer, F., Hummert, E. \& Brückle, I. (2014) Stacked storage system for large works on paper. Restaurator. 35 (3-4), 287-314. Available from: doi: 10.1515/res-2014-0011

Vuckovac, M., Latikka, M., Liu, K., Huhtamäki, T. \& Ras, R. H. A. (2019) Uncertainties in contact angle goniometry. Soft Matter. 15 (35), 7089-7096. Available from: doi: 10.1039/c9sm01221d

Williams, J. C. \& Krasow, M. R. (1973) Folding endurance and tensile strength of paper. Journal of the American Institute for Conservation. 14 (1), 25-32. Available from: doi: 10.1179/019713673806157204

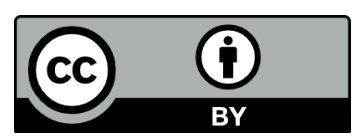

(C) 2022 Authors. Published by the University of Novi Sad, Faculty of Technical Sciences, Department of Graphic Engineering and Design. This article is an open access article distributed under the terms and conditions of the Creative Commons Attribution license 3.0 Serbia (http://creativecommons.org/licenses/by/3.0/rs/). 